\title{
Atmospheric lifetimes and Ozone Depletion Potentials of trans-1-chloro-3,3,3-trifluoropropylene and trans-1,2-dichloroethylene in a three-dimensional model
}

\author{
K. O. Patten and D. J. Wuebbles \\ Department of Atmospheric Sciences, University of Illinois, Urbana, Illinois USA \\ Received: 13 May 2010 - Published in Atmos. Chem. Phys. Discuss.: 2 July 2010 \\ Revised: 21 October 2010 - Accepted: 1 November 2010 - Published: 19 November 2010
}

\begin{abstract}
The chloroalkenes trans-1-chloro-3,3,3trifluoropropylene (tCFP) and trans-1,2-dichloroethylene (tDCE) have been proposed as candidate replacements for other compounds in current use that cause concerns regarding potential environmental effects including destruction of stratospheric ozone. Because tCFP and tDCE contain chlorine atoms, the effects of these short-lived compounds on stratospheric ozone must be established. In this study, we derive the atmospheric lifetimes and Ozone Depletion Potentials (ODPs) for tCFP and for tDCE assuming emissions from land surfaces at latitudes $30^{\circ} \mathrm{N}$ to $60^{\circ} \mathrm{N}$ using the MOZART 3 three-dimensional model of atmospheric chemistry and physics. $53 \%$ of the ozone loss due to tCFP and $98 \%$ of the ozone loss due to tDCE take place in the troposphere, rather than in the stratosphere as generally expected from longer-lived chlorocarbons. The atmospheric lifetime of tCFP against chemical reaction is 40.4 days, and its ODP is quite small at 0.00034 . The tDCE atmospheric lifetime is 12.7 days, and its ODP is 0.00024 , which is the lowest ODP found for any chlorocarbon we have studied. Our study suggests that chlorine from tCFP and tDCE are unlikely to affect ozone at quantities likely to be emitted to the atmosphere.
\end{abstract}

\section{Introduction}

After the destruction of stratospheric ozone by chlorine and bromine released by degradation of human-generated, longlived halocarbon compounds was recognized (reviewed in WMO, 1992, 1995, 1999, 2003, 2007), industry has sought replacement compounds that perform the same functions

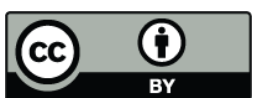

Correspondence to: D. J. Wuebbles (wuebbles@atmos.uiuc.edu) without causing severe environmental effects. Most recent candidate replacement compounds are chosen so that they have short atmospheric lifetimes, and will typically be oxidized rapidly in the troposphere, in order to limit stratospheric ozone loss as well as possible climate effects from those substances.

The Ozone Depletion Potential (ODP; Wuebbles, 1983) of a compound is defined as the reduction in total ozone $\left(\mathrm{O}_{3}\right)$ column per unit of mass for that compound divided by the reduction in total $\mathrm{O}_{3}$ column per unit of mass for the reference compound trichlorofluoromethane $\left(\mathrm{CFCl}_{3}\right.$, often called CFC-11 or Freon-11). This value provides an index of the relative $\mathrm{O}_{3}$ loss to be expected from a compound of interest that can then be used in policy considerations. In our work on candidate replacement compounds, ODPs are calculated using chemical-transport models (CTMs) of the global troposphere and stratosphere. The candidate compound is emitted at the surface in the CTM, and the CTM is run to a steady state. Through comparison to a reference run of the CTM without the candidate compound, we obtain the $\mathrm{O}_{3}$ column reduction for the assumed annual emissions of the compound. A similar comparison for a $\mathrm{CFCl}_{3}$ perturbation in the CTM compared to the reference CTM run yields the $\mathrm{O}_{3}$ column reduction for the ODP reference compound.

The ODP concept was developed originally for ozonedepleting substances that are sufficiently long-lived to mix throughout the troposphere. ODP has recently been extended to shorter-lived replacement compound candidates. The atmospheric lifetime of the candidate and the fraction of the candidate plus its degradation products containing halogen that reaches the stratosphere are dependent on the latitude (possibly also longitude and season) of release, so that the ODP of a short-lived candidate is in general dependent on emission location and time. Because short-lived candidates are not well-mixed throughout the troposphere, a threedimensional CTM should be used, whether directly on the

Published by Copernicus Publications on behalf of the European Geosciences Union. 
candidate (Wuebbles et al., 2001, 2009, 2010; Wuebbles and Patten, 2009) or on a tracer (e.g. Bridgeman et al., 2000; Olsen et al., 2000), to adequately represent the distribution of the compound in the troposphere and the extent of injection of the compound plus halogenated degradation products from the compound into the stratosphere. ODP calculations for a short-lived candidate compound must emphasize the most likely location and season for applications of the candidate due to the expense of three-dimensional CTM calculations, and the location and season of emissions used in obtaining an ODP value is essential information for evaluation of a short-lived candidate compound.

The compounds, trans-1-chloro-3,3,3-trifluoropropylene $\left(\mathrm{t}-\mathrm{CHCl}=\mathrm{CHCF}_{3}\right.$, which we abbreviate as tCFP below) and trans-1,2-dichloroethylene $(\mathrm{t}-\mathrm{CHCl}=\mathrm{CHCl}$, which we abbreviate as $\mathrm{tDCE}$ ), have been proposed as replacements in uses such as electronics cleaning and foam blowing. These compounds include a double bond, which is more reactive toward atmospheric oxidants than are the halogenated alkanes that have typically been considered by industry and environmental policymakers. We obtain the atmospheric lifetime and the ODP for tCFP and for tDCE in this study in a current-generation, three-dimensional CTM of the global atmosphere. This is the first study of atmospheric lifetime and ODP for tCFP and tDCE, and indeed for any halogenated alkene, as far as we are aware.

\section{Method}

Chloroalkenes such as tCFP and tDCE are most readily removed from the atmosphere by oxidation initiated by addition of the hydroxyl $(\mathrm{OH})$ radical, predominantly in the troposphere. This addition reaction can be treated as taking place at the high-pressure limit with a bimolecular rate constant having a weak negative temperature dependence. Possible reactions with other oxidants such as the ground and excited electronic states of oxygen atom $\left(\mathrm{O}\left({ }^{3} \mathrm{P}\right), \mathrm{O}\left({ }^{1} \mathrm{D}\right)\right.$, respectively), nitrogen trioxide $\left(\mathrm{NO}_{3}\right)$, and chlorine atom $(\mathrm{Cl})$ and photolytic degradation are unlikely to be important in the troposphere and lower stratosphere where effectively all oxidation of species with atmospheric chemical lifetimes shorter than one year will occur. The reaction rate constant for tCFP with $\mathrm{OH}$ is taken as $4.4 \times 10^{-13} \mathrm{~cm}^{3} \mathrm{molec}^{-1} \mathrm{~s}^{-1}$, based on the measurement of Sulbaek Andersen et al. (2008) at 295 K, assuming zero temperature dependence. The most recent measurement of the temperature dependence of tDCE reaction with OH we could find is from Zhang et al. (1991), which provided the reaction rate constant for temperature $T$ in Kelvin as $1.01 \times 10^{-12} \exp ((250 \mathrm{~K}) / T) \mathrm{cm}^{3} \mathrm{molec}^{-1} \mathrm{~s}^{-1}$.

For this study, we assume that release of chlorine atoms $(\mathrm{Cl})$ occurs rapidly after the initial $\mathrm{OH}$ addition for both $\mathrm{tCFP}$ and tDCE. The first $\mathrm{Cl}$ is likely to be released quickly from the tDCE-OH adduct, but the further oxidation of the re- maining chloroaldehyde is likely to produce formyl chloride, CHClO (Zhang et al., 1991). In the case of tCFP, oxidation products under atmospheric conditions currently have not been measured, but if $\mathrm{OH}$ adds preferentially to the 1(chlorinated) carbon of tCFP, many of the feasible reaction pathways would produce $\mathrm{CHClO}$ rather than releasing $\mathrm{Cl}$. $\mathrm{CHClO}$ does not react quickly with $\mathrm{OH}$, and is likely to photolyze slowly in the troposphere (Atkinson et al., 2008), so that its gas-phase atmospheric lifetime will be longer than those of tDCE or tCFP and this degradation product could transport $\mathrm{Cl}_{\mathrm{y}}$ to the stratosphere more effectively than the original VSLS. However, $\mathrm{CHClO}$ could dissolve in water or adsorb on ice, and could possibly hydrolyze to $\mathrm{HCl}$ and formic acid on liquid or solid surfaces. Neither the possible heterogeneous processing of $\mathrm{CHClO}$ nor the yield of $\mathrm{CHClO}$ from tCFP under tropospheric conditions are well known at this time, so that we did not incorporate these processes into MOZART 3. If $\mathrm{CHClO}$ heterogeneous processing is slow or results in negligible removal of $\mathrm{Cl}_{\mathrm{y}}$ through wet deposition, our assumption of immediate $\mathrm{Cl}$ release may underestimate ozone effects from tDCE in the atmosphere, but if $\mathrm{CHClO}$ heterogeneous processing results in removal of $\mathrm{Cl}_{\mathrm{y}}$ from the troposphere faster than that of soluble $\mathrm{Cl}_{\mathrm{y}}$ species, our ozone effects calculated for tDCE would be an upper limit. Any effect of this uncertainty on tCFP ozone effects predicted in this study depends on the unknown yield of $\mathrm{CHClO}$ from tCFP oxidation.

The atmospheric mixing ratio profiles and lifetimes of tCFP and tDCE are calculated using the Model for OZone and Related Tracers (MOZART) version 3 (Kinnison et al., 2007), a three-dimensional, global atmospheric chemicaltransport model developed by the National Center for Atmospheric Research (NCAR) which includes a full representation of chemistry and physics affecting the atmosphere from the Earth's surface through the lower thermosphere. MOZART 3 represents the relevant chemical and physical processes affecting the troposphere and stratosphere, including all relevant chemistry in the hydrogen $\left(\mathrm{HO}_{\mathrm{x}}\right)$, nitrogen $\left(\mathrm{NO}_{\mathrm{y}}\right)$, chlorine $\left(\mathrm{Cl}_{\mathrm{y}}\right)$, and bromine $\left(\mathrm{Br}_{\mathrm{y}}\right)$ familes of species important to affecting odd oxygen (ozone $\left(\mathrm{O}_{3}\right), \mathrm{O}\left({ }^{3} \mathrm{P}\right)$, and $\left.\mathrm{O}\left({ }^{1} \mathrm{D}\right)\right)$. MOZART 3 also includes the oxidation chemistry of methane and of non-methane hydrocarbons (NMHCs) that are important to the tropospheric oxidation capacity through their effects on $\mathrm{OH}$. MOZART 3 has been extensively evaluated by comparison to measurements of atmospheric trace gases from aircraft- and satellite-based observations (e.g. Kinnison et al., 2007; Pan et al., 2007).

Thermal and photolytic chemistry data for atmospheric reactions other than those of tCFP and tDCE follow the recommendations of Sander et al. (2003). Meteorology to drive MOZART 3 is from the Whole Atmosphere Community Climate Model (WACCM) version 1b (Sassi et al., 2004) representative of the climatological atmosphere derived for the late 1990s. MOZART 3 driven by this meteorology has a $2.8^{\circ}$ resolution in latitude and in longitude, and the vertical 
grid is a hybrid sigma-pressure coordinate consisting of 66 layers from the surface to $5.1 \times 10^{-6} \mathrm{hPa}$, or approximately $140 \mathrm{~km}$ altitude. In this coordinate, the pressure at each layer $i$ is given by

$P_{i}=a_{i} P_{0}+b_{i} P_{s}$

where $a_{i}$ and $b_{i}$ are the coefficients of the hybrid coordinate for layer $i, P_{0}$ is the reference pressure of $1000 \mathrm{hPa}$, and $P_{\mathrm{s}}$ is the surface pressure, an input from the meteorological fields which depends on surface orography at each latitude and longitude and on time.

MOZART 3 is used to derive the atmospheric lifetimes and Ozone Depletion Potentials (ODPs) of tCFP and tDCE as follows. The background MOZART 3 steady-state atmosphere corresponding roughly to the year 2000 and the CFC-11 perturbation atmosphere needed as the denominator for ODP were previously determined in studies of the ODPs for HCFC-123 (Wuebbles and Patten, 2009) and for n-propyl bromide, trichloroethylene, and perchloroethylene (Wuebbles et al., 2010). The annually and globally-averaged surface mixing ratios of long-lived source gases set as inputs to MOZART 3 are based on those listed in WMO 2002 Scientific Assessment of Ozone Depletion Table 4B-2 (Chipperfield et al., 2003) except for $\mathrm{CO}_{2}, \mathrm{CH}_{4}$, and $\mathrm{N}_{2} \mathrm{O}$ from historic values in Appendix II.2 of the IPCC Third Assessment Report on climate change (IPCC, 2001) linearly interpolated to the year 1999. Surface emissions rates of shortlived source gases except for tCFP and tDCE use the Precursors of Ozone and their Effects in the Troposphere (POET) data base (Granier et al., 2005; Olivier et al., 2003) for the year 2000 as were used in the MOZART 4 evaluation (Emmons et al., 2010).

To obtain atmospheric mixing ratios and chemical lifetimes, tCFP and tDCE are introduced as surface emissions into two separate MOZART 3 runs. These emissions are assumed to occur on all land masses from $30^{\circ} \mathrm{N}$ to $60^{\circ} \mathrm{N}$, which represents the latitude range of the likely short-term usage for either replacement compound (small differences in the resulting effects would be expected if individual regions of North America, Europe or Asia were used instead). The emissions over land from $30^{\circ} \mathrm{N}$ to $60^{\circ} \mathrm{N}$, constant with regard to time of year, are an estimate of emissions patterns for compounds used in industrial processes. A tCFP flux of $1.64 \times 10^{10}$ molecules $\mathrm{cm}^{-2} \mathrm{~s}^{-1}$ is added to MOZART 3, corresponding to a total tCFP emission of $50 \mathrm{Tg}$ per year. The tDCE flux of $2.21 \times 10^{10}$ molecules $\mathrm{cm}^{-2} \mathrm{~s}^{-1}$ introduced to MOZART 3 corresponds to total tDCE emission of $50 \mathrm{Tg}$ per year. The fluxes of tCFP and tDCE introduced to the model are considerably larger than the expected production of these replacement compounds, by comparison to the $0.496 \mathrm{Tg}$ total global demand for all HCFCs during 2002 listed in Campbell et al. (2005). However, such large fluxes of tCFP and tDCE are needed to produce a numerically significant percentage decrease in $\mathrm{O}_{3}$ total column in MOZART 3. The model runs required six years to reach a
Table 1. Annual averaged, global total burdens and atmospheric lifetimes against atmospheric chemical reaction derived for the chloroalkenes trans-1-chloro-3,3,3-trifluoropropylene (tCFP) and trans-1,2-dichloroethylene (tDCE) in MOZART 3.

\begin{tabular}{llll}
\hline Compound & Flux, Tg year & Burden, Tg & Lifetime, days \\
\hline tCFP & 50.0 & 5.54 & 40.4 \\
tDCE & 50.0 & 1.85 & 13.5 \\
tDCE & 16.7 & 0.582 & 12.7 \\
\hline
\end{tabular}

near-steady-state suitable for atmospheric lifetime and ODP analysis.

These large fluxes of a short-lived ozone-depleting substance degraded in the troposphere could alter the $\mathrm{OH}$ field in a CTM, resulting in overestimation of the atmospheric lifetime. The reduction of ozone in the troposphere from the large amount of ozone-depleting substance decreases the amount of $\mathrm{O}\left({ }^{1} \mathrm{D}\right)$ to react with water vapor, decreasing the production term for $\mathrm{OH}$. This possible lifetime distortion is tested for tDCE (the shorter-lived of the two compounds as determined below) by another MOZART 3 run using one-third the flux of the above run $\left(0.737 \times 10^{10}\right.$ molecules $\mathrm{cm}^{-2} \mathrm{~s}^{-1}$, or $\left.16.7 \mathrm{Tg} \mathrm{yr}^{-1}\right)$. We expect that this effect will be smaller for tCFP because this longer-lived species should cause less $\mathrm{O}_{3}$ destruction in the troposphere, so that we did not repeat this test.

\section{Results}

The first quantity to consider when evaluating ozone and climate effects of a potential replacement compound is the atmospheric lifetime, which can be obtained by evaluating the annual average total atmospheric burden divided by the annual, global total input of the compound. Burdens of tCFP and of tDCE for our MOZART 3 runs in this study are listed in Table 1 for each of the assumed surface emissions cases, along with the derived atmospheric lifetimes against atmospheric chemical reaction. The lifetimes in Table 1 are based on the $\mathrm{OH}$ reaction, and do not include the possible, but likely much smaller, additional sinks such as reactions with other oxidants such as $\mathrm{O}_{3}, \mathrm{NO}_{3}$, and $\mathrm{Cl}$, surface deposition, and heterogeneous reactions on clouds or aerosols and thus are upper limits. Both chloroalkenes have short atmospheric lifetimes compared to most compounds they would replace. The lifetime for tCFP is 40.4 days, and that for tDCE with the lower surface emissions input is 12.7 days. The short lifetimes of tCFP and tDCE suggest that these compounds should have little effect on stratospheric ozone and that they should reach the stratosphere only in very limited amounts.

The effect of tropospheric $\mathrm{O}_{3}$ reduction on tDCE lifetime is demonstrated through the difference in lifetimes calculated for $50.0 \mathrm{Tg} \mathrm{year}^{-1}$ versus $16.7 \mathrm{Tg}_{\text {year }}{ }^{-1}$ of tDCE surface 
flux shown in Table 1. The 50.0 Tg year ${ }^{-1}$ run obtained an apparent tDCE lifetime of 13.5 days, six percent higher than that from the $16.7 \mathrm{Tg}_{\mathrm{gear}}{ }^{-1}$ run. This lifetime increase is smaller than the $10 \%$ or greater uncertainty of most reaction rate constants including that for $\mathrm{tDCE}+\mathrm{OH}$ (Zhang et al., 1991). This shows that the OH decrease in the CTM due to tropospheric $\mathrm{O}_{3}$ loss is a minimal but nonzero effect for the $50 \mathrm{Tg}$ year $^{-1}$ run. However, the $50 \mathrm{Tg}_{\mathrm{gear}}{ }^{-1}$ run was needed for an adequate $\mathrm{O}_{3}$ perturbation: the $16.7 \mathrm{Tg}$ year ${ }^{-1}$ run produced less than $0.1 \%$ decrease in total $\mathrm{O}_{3}$ column compared to that of the reference run, which we have found insufficient for numerical stability in ODP calculations.

Figure 1 shows annually and zonally-averaged mixing ratios in ppt of tCFP (part a) and tDCE (part b) obtained in MOZART 3 for emissions corresponding to $50 \mathrm{Tg}$ year $^{-1}$. In this figure and in other figures of approximate pressure versus latitude that follow, the vertical coordinate is the sum of the hybrid sigma-pressure coordinate coefficients times $1000 \mathrm{hPa}$, that is $(1000 \mathrm{hPa}) \times\left(a_{i}+b_{i}\right)$. Annual and zonal mean tropopause pressure, defined by the WMO thermal tropopause criterion of temperature decrease less than $2 \mathrm{~K} \mathrm{~km}^{-1}$ constrained to altitudes of 6 to $18 \mathrm{~km}$, is indicated by white dotted lines on each of these figures. For both tCFP and tDCE in Fig. 1, high mixing ratios are confined to the Northern Troposphere with peak values over 2000 ppt near the surface that decrease strongly toward the tropics or at higher altitudes (lower pressures). The tCFP mixing ratio in the MOZART tropical upper troposphere, shown in Fig. 1a, is around $25 \mathrm{ppt}$ or some $1 \%$ of the peak mixing ratio. Figure $1 \mathrm{~b}$ shows that tDCE is even more strongly constrained to the Northern Troposphere, with mixing ratios below $1.0 \mathrm{ppt}$ throughout the tropical upper troposphere and much of the tDCE shown in the Northern lower stratosphere seemingly transported through the midlatitude tropopause. The burdens of tCFP and tDCE separated into troposphere and stratosphere (and above) components, listed in Table 2, indicate the extent to which these candidate replacement compounds are constrained to the troposphere. Stratospheric tCFP accounts for only $0.84 \%$ of the total burden, and stratospheric tDCE is only $0.12 \%$ of the total burden. By this measure, neither $\mathrm{tCFP}$ nor $\mathrm{tDCE}$ reach the stratosphere to a significant extent even at a surface flux as large as $50 \mathrm{Tg}_{\mathrm{gear}}{ }^{-1}$, as expected from their short lifetimes.

Since tCFP and tDCE do not reach the stratosphere in quantity, transport of $\mathrm{Cl}_{\mathrm{y}}$ produced by oxidation of these replacement compounds from the troposphere to the stratosphere should be considered as a mechanism for secondary injection. Figure 2 shows the chlorine species perturbations from tCFP and from tDCE obtained in MOZART 3 for $50 \mathrm{Tg}$ year $^{-1}$ surface flux of each. Total inorganic chlorine $\mathrm{Cl}_{\mathrm{y}}$ due to tCFP (Fig. 2a) peaks near the southern limit of the emission latitudes and falls off rapidly in the tropics and the Southern Troposphere. The entire MOZART 3 stratosphere has a $\mathrm{Cl}_{\mathrm{y}}$ increase of $25 \mathrm{ppt}$ or more, and a secondary maximum (more than $50 \mathrm{ppt}$ ) of $\mathrm{Cl}_{\mathrm{y}}$ perturbation from tCFP
Table 2. Burdens of tCFP and tDCE calculated in MOZART 3 troposphere and stratosphere for $50.0 \mathrm{Tg}^{\mathrm{year}}{ }^{-1}$ surface flux of each compound.

\begin{tabular}{lllll}
\hline \multirow{2}{*}{ Compound } & \multicolumn{2}{c}{ Troposphere } & \multicolumn{2}{c}{ Stratosphere } \\
& Burden (Tg) & $\%$ of total & Burden $(\mathrm{Tg})$ & $\%$ of total \\
tCFP & 5.494 & 99.16 & 0.046 & 0.84 \\
tDCE & 1.8499 & 99.88 & 0.0023 & 0.12 \\
\hline
\end{tabular}

(a)

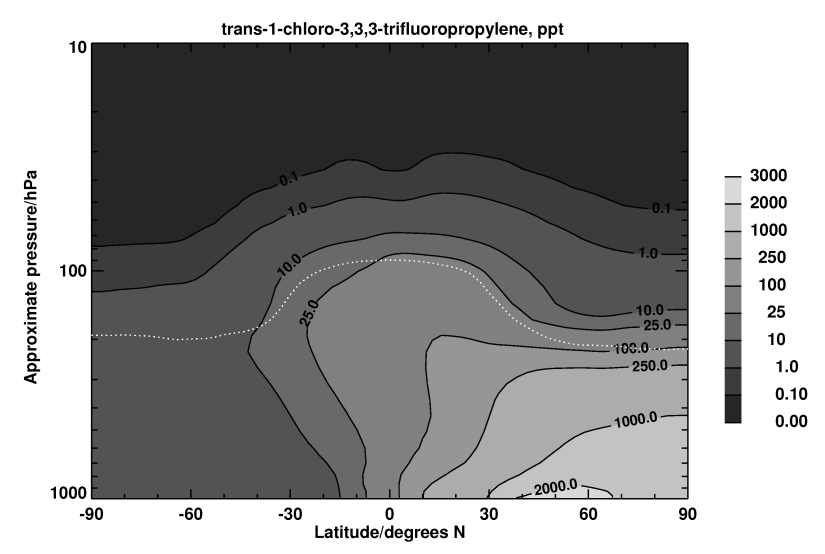

(b)

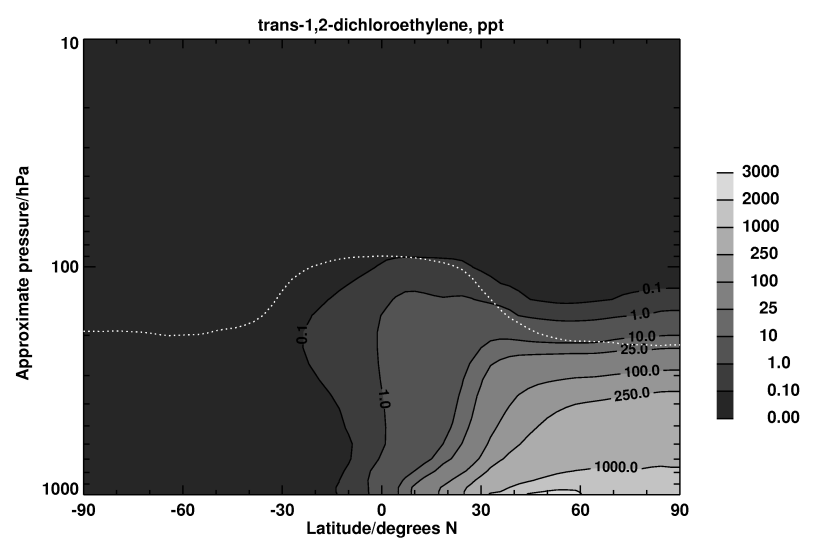

Fig. 1. Annually and zonally-averaged mixing ratio in ppt of the chloroalkenes obtained in MOZART 3 for emissions from the land masses between $30^{\circ} \mathrm{N}$ and $60^{\circ} \mathrm{N}$. In this and the following figures, the white dotted line shows the average tropopause pressure. (a) trans-1-chloro-3,3,3-trifluoropropylene (tCFP) at $1.64 \times 10^{10}$ molec cm $^{-2} \mathrm{~s}^{-1}$. (b) trans-1,2-dichloroethylene (tDCE) at $2.21 \times 10^{10}$ molec $\mathrm{cm}^{-2} \mathrm{~s}^{-1}$.

ranges from the North Polar lower stratosphere to the tropics. Comparison to the tCFP perturbation in Fig. 1a suggests that about half of the $\mathrm{Cl}_{\mathrm{y}}$ perturbation from tCFP is due to $\mathrm{Cl}_{\mathrm{y}}$ transport from the troposphere. 
(a)

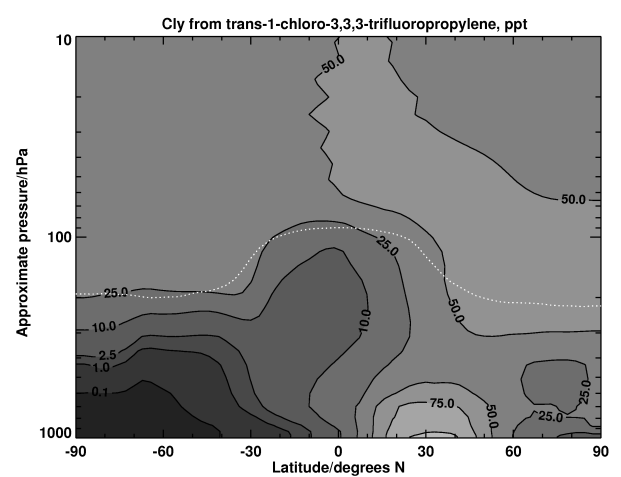

(b)

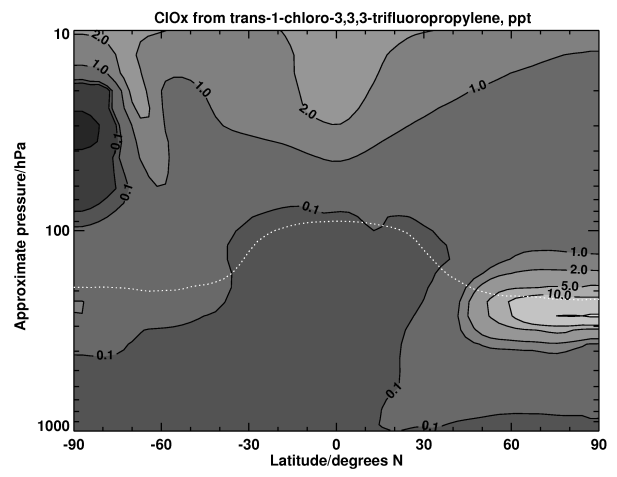

(c)

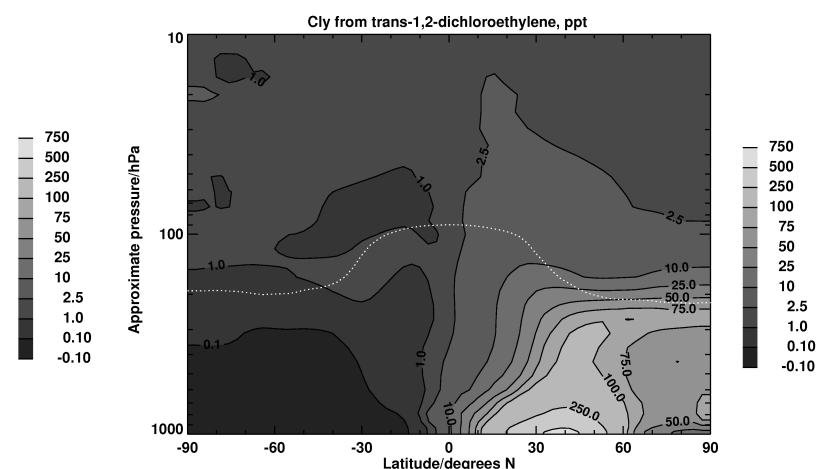

(d)

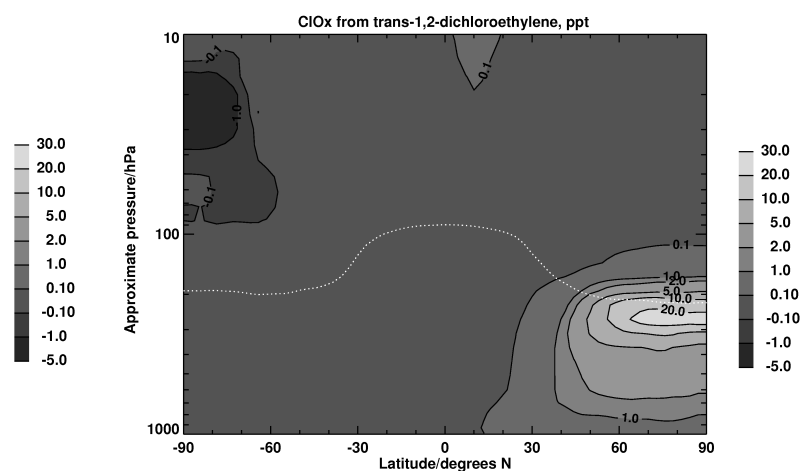

Fig. 2. Annual and zonally- average chlorine perturbations (mixing ratio, ppt) in MOZART 3 resulting from the chloroalkene source gases. (a) All inorganic chlorine $\left(\mathrm{Cl}_{\mathrm{y}}\right)$ from tCFP. (b) Reactive chlorine $\left(\mathrm{ClO}_{\mathrm{x}}\right)$ from tCFP. (c) $\mathrm{Cl}_{\mathrm{y}}$ from tDCE. (d) $\mathrm{ClO}$ from tDCE.

Only the fraction of $\mathrm{Cl}_{\mathrm{y}}$ that reacts with odd oxygen species $\mathrm{O}_{\mathrm{x}}=\mathrm{O}_{3}+\mathrm{O}\left({ }^{3} \mathrm{P}\right)+\mathrm{O}\left({ }^{1} \mathrm{D}\right)$ is destructive to ozone. Figure $2 \mathrm{~b}$ shows the annual and zonally-averaged change in $\mathrm{ClO}_{\mathrm{x}}=\mathrm{Cl}+\mathrm{ClO}$, those $\mathrm{Cl}_{\mathrm{y}}$ species most reactive to the $\mathrm{O}_{\mathrm{x}}$ species, as calculated in MOZART 3. Despite increases in $\mathrm{Cl}_{\mathrm{y}}$ of at least $10 \mathrm{ppt}$ throughout much of the region shown, the most prominent increase in $\mathrm{ClO}_{\mathrm{x}}$ is that in the upper troposphere to lower stratosphere for latitudes north of $40^{\circ} \mathrm{N}$, although increases over $1 \mathrm{ppt}$ exist throughout most of the stratosphere except for a decrease in the region subject to polar stratospheric cloud (PSC) chemistry.

The shorter lifetime of tDCE more effectively constrains $\mathrm{Cl}_{\mathrm{y}}$ perturbations to the Northern Troposphere and lower stratosphere below the tropical tropopause, as shown in Fig. 2c. The maximum $\mathrm{Cl}_{\mathrm{y}}$ perturbation, over $500 \mathrm{ppt}$, appears within emission latitudes near the surface. $\mathrm{The} \mathrm{Cl}_{\mathrm{y}}$ perturbation extends upward and crosses into the stratosphere predominantly at mid-latitudes: $\mathrm{Cl}_{\mathrm{y}}$ perturbation is no higher than $10 \mathrm{ppt}$ at the tropopause for latitudes south of $20^{\circ} \mathrm{N}$, and even in the Northern latitudes, the $10 \mathrm{ppt}$ contour never reaches an altitude greater than the $150 \mathrm{hPa}$ layer within the lower stratosphere. The $\mathrm{ClO}_{\mathrm{x}}$ increase resulting from the in-
Table 3. Ozone Depletion Potentials (ODPs) derived for tCFP and for tDCE.

\begin{tabular}{ll}
\hline $\begin{array}{l}\text { Candidate } \\
\text { Compound }\end{array}$ & ODP \\
\hline tCFP & 0.00034 \\
tDCE & 0.00024 \\
\hline
\end{tabular}

troduction of tDCE, shown in Fig. 2d, is effectively contained in the Northern Troposphere and lower stratosphere; a $\mathrm{ClO}_{\mathrm{x}}$ decrease appears in the PSC region as with tCFP in Fig. $2 b$.

Minimal $\mathrm{ClO}_{\mathrm{x}}$ increases in the stratosphere indicate that much of the $\mathrm{O}_{3}$ loss from tCFP and tDCE can be expected to be contained within the Northern Troposphere and lower stratosphere. Figure 3 shows the annual and zonal mean $\mathrm{O}_{3}$ mixing ratio perturbation from $\mathrm{tCFP}$ (Fig. $3 \mathrm{a}$ ) and from tDCE (Fig. 3b) compared to the reference atmosphere in percent. Most of the stratosphere in Fig. 3a has $\mathrm{O}_{3}$ within $0.1 \%$ of that for the reference run, and mixing ratio decreases of $1 \%$ or more exist only in the Northern Troposphere and lowermost stratosphere and in the South Polar upper troposphere/lower 
Table 4. Annually averaged, global tropospheric and stratospheric ozone burden changes (Tg) calculated in MOZART 3 for surface fluxes of tCFP and of tDCE.

\begin{tabular}{|c|c|c|c|c|c|}
\hline \multirow[t]{2}{*}{ Compound } & \multirow{2}{*}{$\begin{array}{l}\text { Surface flux, } \\
\text { Tg year }^{-1}\end{array}$} & \multicolumn{2}{|c|}{ Troposphere } & \multicolumn{2}{|c|}{ Stratosphere } \\
\hline & & $\begin{array}{l}\Delta \mathrm{O}_{3} \\
\text { burden }(\mathrm{Tg})\end{array}$ & $\begin{array}{l}\% \text { of } \\
\text { change }\end{array}$ & $\begin{array}{l}\Delta \mathrm{O}_{3} \\
\text { burden }(\mathrm{Tg})\end{array}$ & $\begin{array}{l}\% \text { of } \\
\text { change }\end{array}$ \\
\hline tCFP & 50.0 & 5.756 & 53.1 & 5.093 & 46.9 \\
\hline $\mathrm{tDCE}$ & 50.0 & 9.870 & 96.5 & 0.361 & 3.5 \\
\hline $\mathrm{tDCE}$ & 16.7 & 3.192 & 98.1 & 0.061 & 1.9 \\
\hline
\end{tabular}

stratosphere region. For the tDCE perturbation in Fig. 3b, $\mathrm{O}_{3}$ decreases by $1 \%$ or more only in the Northern Troposphere and lowermost stratosphere, and indeed $\mathrm{O}_{3}$ in parts of the Southern and lower tropical Stratosphere increases by more than $0.1 \%$.

As part of the ODP calculation, the change in annually averaged total $\mathrm{O}_{3}$ column due to emission of tCFP and of tDCE incorporated into MOZART 3 is evaluated. ODPs obtained from these calculations with respect to the $\mathrm{O}_{3}$ column perturbation obtained in the previous CFC-11 run (Wuebbles and Patten, 2009) are listed in Table 3. The ODP of tCFP is 0.00034 , and that of tDCE is 0.00024 . These are the lowest ODPs obtained for chlorocarbon species in our chemicaltransport modeling of ozone-depleting substances. These low ODPs suggest that the $\mathrm{O}_{3}$ effects of industrial emissions up to $50 \mathrm{Tg} / \mathrm{yr}$, some 100 times the 2002 global HCFC demand (Campbell et al., 2005), over the latitude range $30^{\circ} \mathrm{N}$ to $60^{\circ} \mathrm{N}$ should be minimal. However, if $\mathrm{CHClO}$ is adequately long-lived in the troposphere to transport significant $\mathrm{Cl}_{\mathrm{y}}$ to the stratosphere, these ODPs underestimate the tDCE stratospheric ozone loss and could underestimate that of tCFP if its oxidation produces significant $\mathrm{CHClO}$.

A calculation similar to that of $\mathrm{O}_{3}$ column change for ODP can be used to separate $\mathrm{O}_{3}$ column changes into tropospheric and stratospheric (and above) components, and multiplication of these column components by the area of Earth gives the changes in $\mathrm{O}_{3}$ tropospheric and stratospheric burden due to the compound. Table 4 lists the changes in $\mathrm{O}_{3}$ tropospheric and stratospheric burden from tCFP and tDCE in MOZART 3. For the $50 \mathrm{Tg}$ year $^{-1}$ surface emissions of each compound, the total reduction of $\mathrm{O}_{3}$ burden is approximately $10 \mathrm{Tg}$, but the fraction of $\mathrm{O}_{3}$ burden decrease in the stratosphere is nearly half for tCFP, but only $3.5 \%$ for tDCE. Though the total $\mathrm{O}_{3}$ change in the $16.7 \mathrm{Tg}$ year $^{-1}$ tDCE test may be too low to provide a reliable ODP, we proceeded with the $\mathrm{O}_{3}$ burden calculations for Table 4, and the stratospheric $\mathrm{O}_{3}$ burden decrease at this lower tDCE flux decreases to $1.9 \%$. High tDCE fluxes in MOZART 3 cause stronger $\mathrm{O}_{3}$ losses that in turn reduce $\mathrm{OH}$ concentrations in the Northern Troposphere sufficiently that a slightly larger fraction of the $\mathrm{Cl}_{\mathrm{y}}$ perturbation from tDCE reaches the stratosphere to cause $\mathrm{O}_{3}$ depletion. Notably, Table 4 and Fig. 3 show that 53\%, or over half, of the $\mathrm{O}_{3}$ depletion arising from tCFP and $98 \%$, (a)

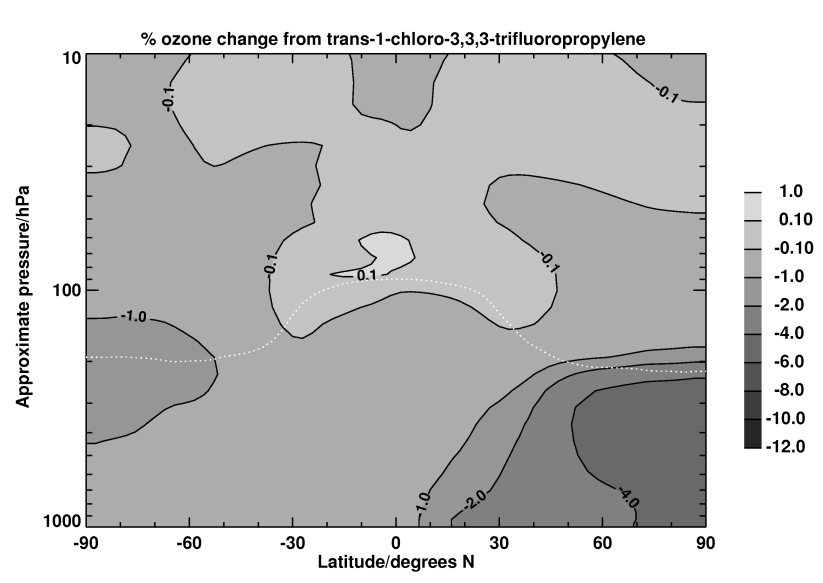

(b)

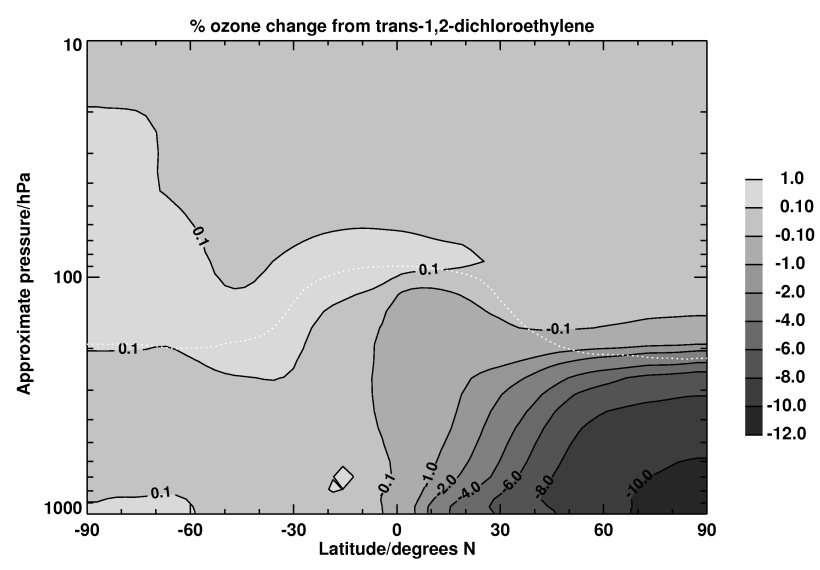

Fig. 3. Annual and zonally-averaged percent change in ozone arising from the chloroalkenes in MOZART 3. (a) tCFP, (b) tDCE.

or nearly all, of that from tDCE would occur in the troposphere, rather than the stratospheric ozone layer where most of the long-lived ozone-depleting substances cause $\mathrm{O}_{3}$ loss. 


\section{Summary}

Atmospheric lifetimes and Ozone Depletion Potentials (ODPs) have been derived for the two chloroalkenes 1-chloro-3,3,3-trifluoropropylene (tCFP) and trans-1,2dichloroethylene (tDCE) using the MOZART 3 chemicaltransport model of the global atmosphere. When emitted from land surfaces in the latitude range $30^{\circ} \mathrm{N}$ to $60^{\circ} \mathrm{N}$ in MOZART, the atmospheric lifetime of tCFP is 40.4 days, and its ODP is 0.00034 . Emission of tDCE from the same locations in MOZART gives an atmospheric lifetime of 12.7 days and an ODP of 0.00024 for that compound. These ODPs were obtained under the assumption that chlorine is released rapidly from tCFP and tDCE; the possibility exists that formyl chloride, $\mathrm{CHClO}$, produced by oxidation of these compounds could transport chlorine to the stratosphere and result in larger ozone losses than shown, but its fate in the atmosphere is not well known. Based on these results, industrial uses of these compounds are unlikely to lead to ozone depletion effects. Within the assumption of quick chlorine release, much of the minimal ozone loss that does result from these compounds, especially tDCE, occurs in the troposphere.

Edited by: J. G. Murphy

\section{References}

Atkinson, R., Baulch, D. L., Cox, R. A., Crowley, J. N., Hampson, R. F., Hynes, R. G., Jenkin, M. E., Rossi, M. J., Troe, J., and Wallington, T. J.: Evaluated kinetic and photochemical data for atmospheric chemistry: Volume IV gas phase reactions of organic halogen species, Atmos. Chem. Phys., 8, 4141-4496, doi:10.5194/acp-8-4141-2008, 2008.

Bridgeman, C. H., Pyle, J. A., and Shallcross, D. E.: A threedimensional model calculation of the ozone depletion potential of 1-bromopropane (1- $\left.\mathrm{C}_{3} \mathrm{H}_{7} \mathrm{Br}\right)$, J. Geophys. Res., 105, 26493 26502, 2000.

Campbell, N., Shende, R., Bennett, M., Blinova, O., Derwent, R., McCulloch, A., Yamabe, M., Shevlin, J., Vink, T., Ashford, P., Midgley, P., and McFarland, M.: HFCs and PFCs: Current and Future Supply, Demand, and Emissions, plus Emissions of CFCs, HCFCs and Halons, Safeguarding the Ozone Layer and the Global Climate System: Issues Related to Hydrofluorocarbons and Perfluorocarbons, Intergovernmental Panel on Climate Change/Technology and Economic Assessment Panel Special Report, Cambridge University Press, New York, New York, USA, chapter 11, 403-435, 2005.

Chipperfield, M. P., Randel, W. J., Bodeker, G. E., Dameris, M., Fioletov, V. E., Friedl, R. R., Harris, N. R. P., Logan, J. A., McPeters, R. D., Muthama, N. J., Peter, T., Shepherd, T. G., Shine, K. P., Solomon, S., Thomason, L. W., Zawodny, J. M., and contributors: Global Ozone: Past and Future, World Meteorological Organization Scientific Assessment of Ozone Depletion: 2002, Global Ozone Research and Monitoring ProjectReport No. 47, Geneva, Switzerland, chapter 4, 2003.

Emmons, L. K., Walters, S., Hess, P. G., Lamarque, J.-F., Pfister, G. G., Fillmore, D., Granier, C., Guenther, A., Kinnison, D.,
Laepple, T., Orlando, J., Tie, X., Tyndall, G., Wiedinmyer, C., Baughcum, S. L., and Kloster, S.: Description and evaluation of the Model for Ozone and Related chemical Tracers, version 4 (MOZART-4), Geosci. Model Dev., 3, 43-67, 2010.

Granier, C., Guenther, A., Lamarque, J., Mieville, A., Müller, J., Olivier, J., Orlando, J., Peters, J., Petron, G., Tyndall, G., and Wallens, S.: POET, a database of surface emissions of ozone precursors, available at: http://www.aero.jussieu.fr/projet/ ACCENT/POET.php, 2005.

Intergovernmental Panel on Climate Change (IPCC): Climate Change 2001: The Scientific Basis, edited by: Houghton, J., Ding, Y., Griggs, D. J., Noguer, M., van der Linden, P. J., Dai, X., Maskell, K., and Johnson, C. A., Cambridge University Press, Cambridge, United Kingdom, Appendix II, 2001.

Kinnison, D. E., Brasseur, G. P., Walters, S., Garcia, R. R., Marsh, D. R., Sassi, F., Harvey, V. L., Randall, C. E., Emmons, L., Lamarque, J. F., Hess, P., Orlando, J. J., Tie, X. X., Randel, W., Pan, L. L., Gettelman, A., Granier, C., Diehl, T., Niemeier, U., and Simmons, A. J.: Sensitivity of chemical tracers to meteorological parameters in the MOZART-3 chemical transport model, J. Geophys. Res. 112, D20302, doi:10.1029/2006JD007879, 2007.

Olsen, S. C., Hannegan, B. J., Zhu, X., and Prather, M. J.: Evaluating ozone depletion from very short-lived halocarbons, Geophys. Res. Lett., 27, 1475-1478, 2000.

Olivier, J., Peters, J., Granier, C., Petron, G., Müller, J., and Wallens, S.: Present and future surface emissions of atmospheric compounds, POET report \#2, EU project EVK2-199900011, available at: http://www.aero.jussieu.fr/projet/ACCENT/ Documents/del2_final.doc, 2003.

Pan, L., Wei, J. C., Kinnison, D. E., Garcia, R. R., Wuebbles, D. J., and Brasseur, G. P.: A set of diagnostics for evaluating chemistry-climate models in the extratropical tropopause region, J. Geophys. Res., 112, D09316, doi:10.1029/2006JD007792, 2007.

Sander, S. P., Friedl, R. R., Golden, D. M., Kurylo, M. J., Huie, R. E., Orkin, V. L., Moortgat, G. K., Ravishankara, A. R., Kolb, C. E., Molina, M. J., and Finlayson-Pitts, B. J.: Chemical Kinetics and Photochemical Data for Use in Atmospheric Studies, Evaluation Number 14, JPL Publication 02-25, NASA Panel for Data Evaluation, Jet Propulsion Laboratory, California Institute of Technology, Pasadena, California, available at: http://jpldataeval.jpl.nasa.gov, 2003.

Sassi, F., Kinnison, D. E., Boville, B. A., Garcia, R. R., and Roble, R.: Effect of El Niño-Southern Oscillation on the dynamical, thermal, and chemical structure of the middle atmosphere, J. Geophys. Res., 109, D17108, doi:10.1029/2003JD004434, 2004.

Sulbaek Andersen, M. P., Nilsson, E. J. K., Nielsen, O. J., Johnson, M. S., Hurley, M. D., and Wallington, T. J.: Atmospheric chemistry of trans- $\mathrm{CF}_{3} \mathrm{CH}=\mathrm{CHCl}$ : Kinetics of the gas-phase reactions with $\mathrm{Cl}$ atoms, $\mathrm{OH}$ radicals, and $\mathrm{O}_{3}$, J. Photochem. Photobiol. A: Chem., 199, 92-97, 2008.

World Meteorological Organization (WMO): Scientific Assessment of Ozone Depletion: 1991, Global Ozone Research and Monitoring Project - Report No. 25, WMO, Geneva, Switzerland, 1992.

World Meteorological Organization (WMO): Scientific Assessment of Ozone Depletion: 1994, Global Ozone Research and Monitoring Project - Report No. 37, WMO, Geneva, Switzerland, 1995.

World Meteorological Organization (WMO): Scientific Assessment 
of Ozone Depletion: 1998, Global Ozone Research and Monitoring Project - Report No. 44, WMO, Geneva, Switzerland, 1999.

World Meteorological Organization (WMO): Scientific Assessment of Ozone Depletion: 2002, Global Ozone Research and Monitoring Project - Report No. 47, WMO, Geneva, Switzerland, 2003.

World Meteorological Organization (WMO): Scientific Assessment of Ozone Depletion: 2006, Global Ozone Research and Monitoring Project - Report No. 50, WMO, Geneva, Switzerland, 2007.

Wuebbles, D. J.: Chlorocarbon emission scenarios: potential impact on stratospheric ozone, J. Geophys. Res., 88, 1433-1443, 1983.

Wuebbles, D. J., Patten, K. O., Johnson, M. T., and Kotamarthi, R.: New methodology for Ozone Depletion Potentials of short-lived compounds: n-Propyl bromide as an example, J. Geophys. Res. 106, 14551-14571, 2001.

Wuebbles, D. J. and Patten, K. O.: Three-Dimensional Modeling of HCFC-123 in the Atmosphere: Assessing Its Potential Environmental Impacts and Rationale for Continued Use, Environ. Sci. Technol., 43, 3208-3213, 2009.
Wuebbles, D. J., Youn, D., Patten, K., Wang, D., and MartínezAvilés, M.: Metrics for Ozone and Climate: Three-Dimensional Modeling Studies of Ozone Depletion Potentials and Indirect Global Warming Potentials, Twenty Years of Ozone Decline, edited by: Zerefos, C., Contopoulos, G., and Skalkeas, G., Springer Science and Business Media, Athens, Greece, 297-326, 2009.

Wuebbles, D. J., Patten, K. O., Wang, D., Youn, D., MartínezAvilés, M., and Francisco, J. S.: Three-dimensional model evaluation of the Ozone Depletion Potentials for n-propyl bromide, trichloroethylene and perchloroethylene, Atmos. Chem. Phys. Discuss., 10, 17889-17910, doi:10.5194/acpd-10-17889-2010, 2010.

Zhang, Z., Liu, R., Huie, R. E., and Kurylo, M. J., A Gas-Phase Reactivity Study of $\mathrm{OH}$ Radicals with 1,1-Dichloroethene and cis- and trans-1,2-Dichloroethene over the Temperature Range 240-400 K, J. Phys. Chem., 95, 194-196, 1991. 